\title{
Non-Contact Terahertz Inspection of Water Content in Concrete of Infrastructure Buildings
}

\author{
Tadao Tanabe1, Tomoya Kanai', Kenta Kuroo'1, Tomoya Nishiwaki², \\ Yutaka Oyama ${ }^{1}$
}

\footnotetext{
${ }^{1}$ Department of Materials Science, Graduate School of Engineering, Tohoku University, Sendai, Japan

${ }^{2}$ Department of Architecture and Building Science, Graduate School of Engineering, Tohoku University, Sendai, Japan

Email: tadao.tanabe.b1@tohoku.ac.jp
}

How to cite this paper: Tanabe, T., Kanai, T., Kuroo, K., Nishiwaki, T. and Oyama, Y. (2018) Non-Contact Terahertz Inspection of Water Content in Concrete of Infrastructure Buildings. World Journal of Engineering and Technology, 6, 275-281. https://doi.org/10.4236/wjet.2018.62016

Received: February 20, 2018

Accepted: May 8, 2018

Published: May 11, 2018

Copyright (c) 2018 by authors and Scientific Research Publishing Inc. This work is licensed under the Creative Commons Attribution International License (CC BY 4.0).

http://creativecommons.org/licenses/by/4.0/

\begin{abstract}
Concrete is the most widely used for construction materials in the world. Water content of concrete is an important parameter in terms durability of concrete structures. Terahertz $(\mathrm{THz})$ waves, for which concrete is a porous and absorbable material, have been studied in order to establish a new non-contact inspection technology for maintenance of concrete structures. In this study, $\mathrm{THz}$ transmittance and reflectance of concrete in drying process were measured with a $60 \mathrm{GHz}$ GUNN diode and absorption coefficient is analyzed for concrete with various water contents. It is shown that quantitative detection below $10 \%$ is possible for the water content at surface area of concrete.
\end{abstract}

\section{Keywords}

Concrete, Water Content, Terahertz Wave, Noncontact Inspection

\section{Introduction}

\subsection{Terahertz Waves and Applications}

Terahertz $(\mathrm{THz})$ waves are electromagnetic waves in the frequency range between approximately 0.1 and $10 \mathrm{THz}$, which is just the middle of the radio wave and the light wave. Therefore, $\mathrm{THz}$ wave has both of characteristics as represented by transparency of radio wave to non-polarized substance and good reflectivity to metal of light wave.

$1 \mathrm{THz}$ corresponds to quantum energy of about $4.1 \mathrm{meV}$, which is relatively as low as one hundred thousandth of X-ray. Hence, it is safe for human body. THz waves are expected as non-destructive evaluation. Our group has created a database of $\mathrm{THz}$ permeability characteristics for industrial materials, and successfully 
constructed non-destructive $\mathrm{THz}$ diagnosis of building blocks [1], insulated copper cable [2], hot-dip galvanized steel sheet and banknotes [3]. Furthermore, the energy of a $\mathrm{THz}$ wave corresponds to molecular interactions such as hydrogen bonding, van der Waals interactions and lattice interactions. The lattice interaction is affected by a mechanical deformation of polymer. THz spectroscopy can be used for non-destructive diagnosis of mechanical deformation in polymers [4]. By other researchers, the non-destructive $\mathrm{THz}$ imaging inspection has been applied to space-shuttle ceramic style bonded state [5], tablet surface defect analysis [6], in the medical field, non-destructive inspection of cancer cell [7].

In this study, we report the non-contact inspection of water content inside the concrete by sub- $\mathrm{THz}$ waves which are relatively low frequency in the $\mathrm{THz}$ band. Water has a large absorption in the $\mathrm{THz}$ frequency region. $\mathrm{THz}$ wave has a high sensitivity in detecting water in concrete. Based on quantitative relation between $\mathrm{THz}$ absorption coefficient and water content, which is measured in this study, non-destructive $\mathrm{THz}$ inspection is available for water content in concrete of infrastructure buildings itself. $\mathrm{THz}$ wave generator and detector are recently developed with small size.

\subsection{Concrete}

From the Roman period, concrete is widely used in our lives such as buildings, bridges, dams due to its good mechanical properties, durability, workablity, and accessibility with low economical cost. To establish a sustainable society, the durability of concrete structures with proper maintenance work becomes more and more important. When constructing a new concrete, it is not obtaining strength from the beginning. It obtains strength by hydration reaction by mixing cement and water in casting. In case that enough water is not provided at the early hydration stage, concrete has risks of insufficient strength and durability due to rough microstructure. Moreover, corrosion of reinforcing steel bars of concrete structure is strongly affected by the presence of water. Therefore, it is important to measure the water content at concrete structures.

As a traditional inspection method for the water content in concrete, a high frequency capacitance measurement method is available now [8] [9] [10]. In this method, an alternating current of $20 \mathrm{MHz}$ is passed through the sample, and its dielectric constant change is measured as the water amount. The dielectric constant of various materials is 10 or less when air is 1 , but water is 80 , so the apparent dielectric constant greatly increases when water is contained. Therefore, if the relation between water and dielectric constant is obtained beforehand, the water content of the sample can be calculated by measuring the dielectric constant. Although this method can inspect water content, it has disadvantage such as contact method and necessary of sample information, for example specific gravity and thickness. Therefore, in this study, we describe a contactless method to measure water content of concrete by using $\mathrm{THz}$ waves. 


\section{Materials and Methods}

\subsection{Measurement Sample}

Figure 1 shows photograph of the concrete test sample. As the measurement sample, a concrete sample prepared with following mix proportion; $32 \mathrm{MPa}$ of the design strength, 0.62 of the water/cement ratio, $15 \mathrm{~cm}$ of the target slump, $273 \mathrm{~kg} / \mathrm{m}^{3}$ of the unit cement content, and $4.5 \%$ of the target air content. Crushed stone is used as coarse aggregate and sand is used as fine aggregate. The diameter of sample is $30 \mathrm{~mm}$ and the thickness of the sample is cut to $7 \mathrm{~mm}$ and $13.5 \mathrm{~mm}$. When this sample leave at the condition of concrete including water up to the maximum, the mass varied like Figure 2. And this mass change was considered to be the evaporation of water and the water content at the measurement time was calculated by

$$
u=\frac{m-m_{0}}{m_{0}} \times 100
$$

which $u$ is water content, $m$ is mass at measurement and $m_{0}$ is mass at dry condition. In this study, transmittance and reflection intensity measurements were carried out for the concrete as a function of water content.

\subsection{THz Transmittance and Reflection Measurement}

A schematic diagram of the transmittance and reflection measurement system is shown in Figure 3. A $60 \mathrm{GHz}$ GUNN diode is used for the THz source. Since the light source is continuous wave, it has sufficient and steady intensity. Hence, we did not use the lock-in amplifier. The generated $\mathrm{THz}$ waves are collimated by a Teflon lens and then focused on the surface of sample by Teflon lens. The beam diameter of the light source is an ellipse with a width of $28 \mathrm{~mm}$ and a length of $26 \mathrm{~mm}$. The transmitted and reflected $\mathrm{THz}$ waves from the sample are collected by Teflon lens, and the transmitted and reflected waves are detected by a Schottky barrier diode, respectively. In this study, we set the sample with maximum water content into the optical system and measured the transmittance and reflection and intensity as a function of leaving time.

\section{Results and Discussion}

Using the transmittance and the reflectance obtained by this measurement, the absorption coefficient was calculated by

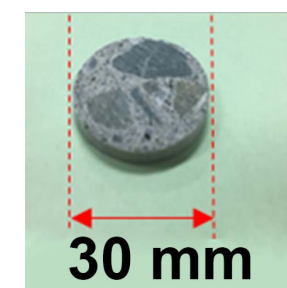

Figure 1. Photographs of the concrete test sample. 


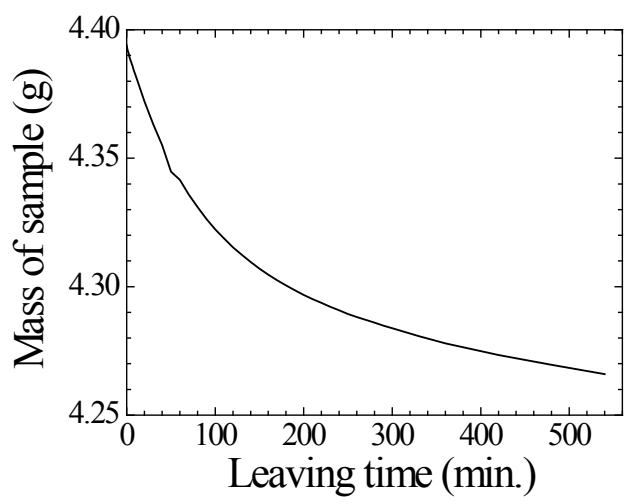

Figure 2. Mass change of concrete by leaving.

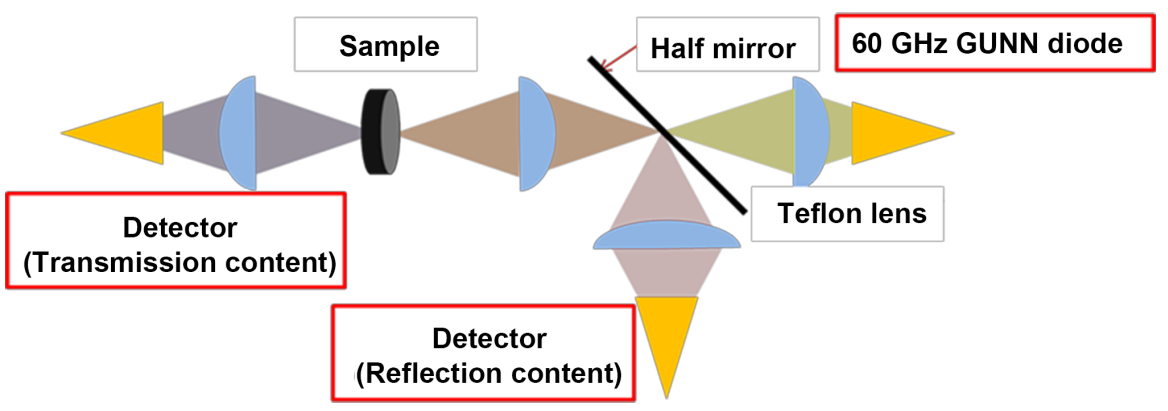

Figure 3. The optical schematic system of $\mathrm{THz}$ transmittance and reflection measurement.

$$
\alpha=-\frac{\ln \left(\frac{T}{100-R}\right)}{x}
$$

which $T$ is transmittance, $R$ is reflectance and $x$ is width of sample [11]. The relationship between the absorption coefficient and the water content in each sample is shown in Figure 4. For $7 \mathrm{~mm}$ thickness, we prepared two samples with different water content. From this result, it can be seen that the absorption coefficient increases with increase of the water content in both samples. It shows that the absorption of $\mathrm{THz}$ waves increases as the amount of water increases, but as shown in Figure 5, the absorption coefficient rapidly increases around 10\% water content. In the lower water content region, the change in the absorption coefficient is slight, which is attributed to hydrated water in concrete. The absorption coefficient at $0 \%$ water content is that of dry concrete itself. In the high water around $10 \%$, the absorption coefficient changes rapidly, which is assigned to free water [12] [13]. Assuming that the amount of change in absorption coefficient per $1 \%$ water content as the sensitivity in this study, which is slope in Figure 5, the sensitivity with hydrated water is 0.02 and the sensitivity with water is 0.36 . The possibility of measuring the quantitative water content inside the concrete by $\mathrm{THz}$ wave is up to $10 \%$.

Since it is difficult to measure the transmission wave from the sample in the field measurement, we consider the quantitative detection possibility using only 


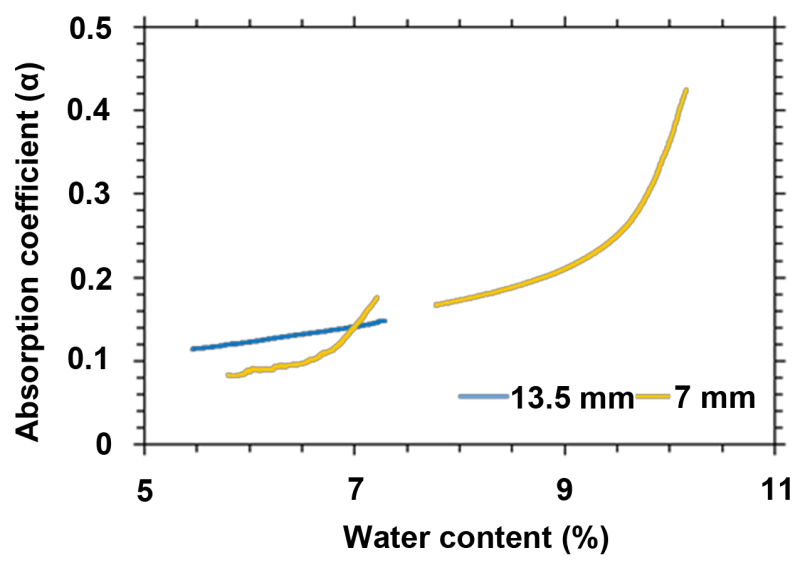

Figure 4. Relationship between water content and absorption coefficient.

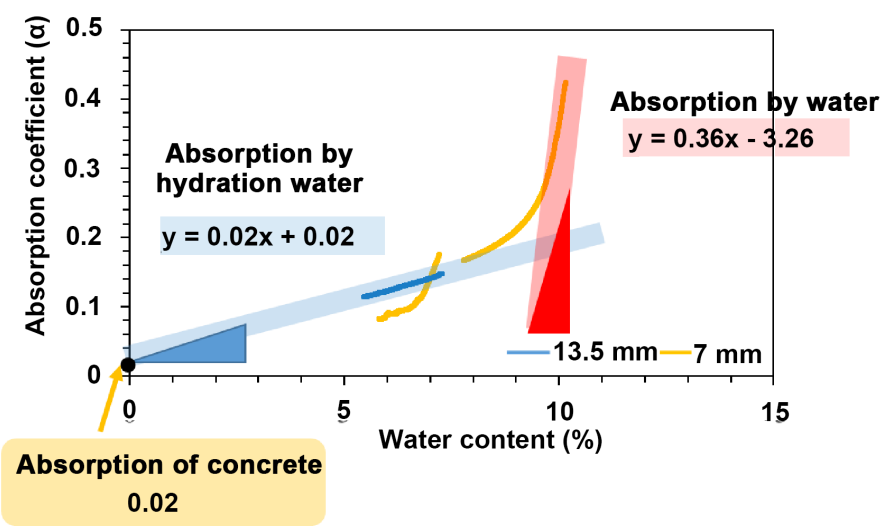

Figure 5. Relationship between thickness and sensitivity.

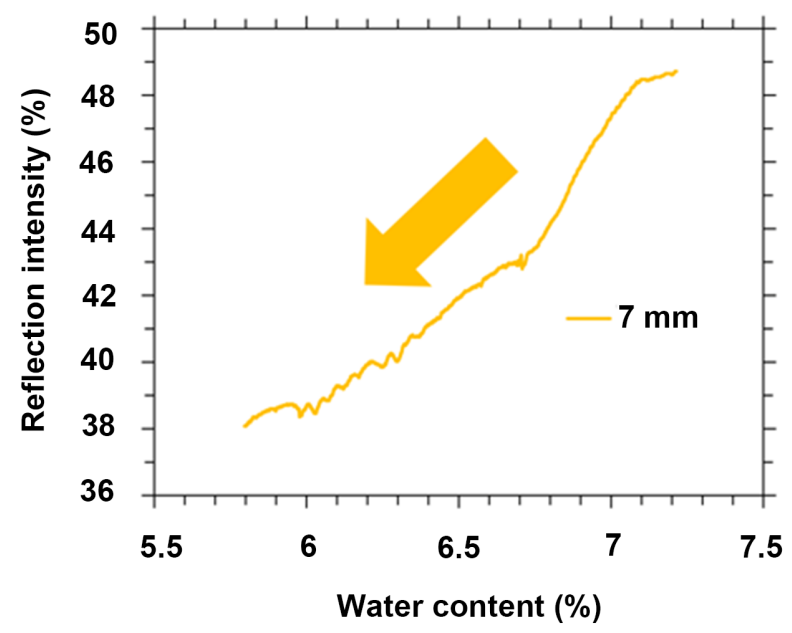

Figure 6. Reflection intensity from the concrete of $7 \mathrm{~mm}$ thickness.

the reflected wave. The measurement result of the reflection intensity from the concrete when the thickness is $7 \mathrm{~mm}$ is shown in Figure 6. In this result, as the water content decreases, the reflection intensity decreases. This is because the 
High water content

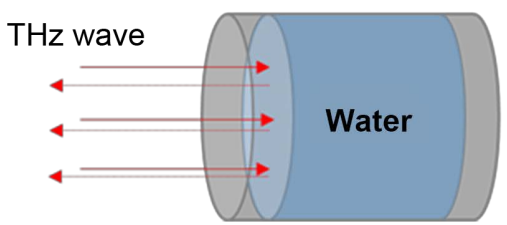

Low water content

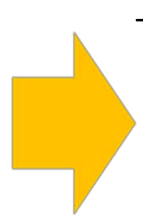

THz wave

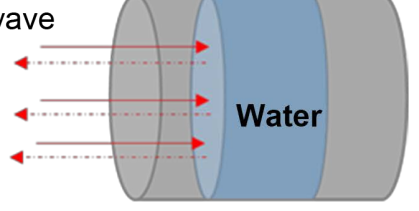

Figure 7. Difference in reflection behavior due to moisture content.

water evaporates from the surface, the $\mathrm{THz}$ wave penetrates deeper and the absorption of the $\mathrm{THz}$ wave by the concrete becomes larger. From Figure 5, the absorption of $\mathrm{THz}$ waves increases by increasing the water content, but the reason for the opposite result is that because the water evaporates from the surface, the $\mathrm{THz}$ wave penetrates deeper and the absorption of the $\mathrm{THz}$ wave by the concrete becomes larger like Figure 7. This result showed the possibility of measuring the distribution of water inside the concrete.

\section{Conclusion}

For concrete with 0 - 10 water contents, absorption coefficient was measured using $60 \mathrm{GHz}$ emitter at room temperature. The absorption coefficient increases slowly with increasing water content up to $10 \%$. This feature can be taken as evidence for hydrated water in concrete. Above $10 \%$, the absorption coefficient increases steeply, which is attributed to free water. The water content can be measured below $10 \%$ at surface area of concrete.

\section{Acknowledgements}

This study is partially supported by "Fundamental Research and Human Resources Development Program for Nuclear Decommissioning related to Integrity Management of Critical Structures including Primary Containment Vessel and Reactor Building, and Fuel Debris Processing and Radioactive Waste Disposal" carried out under the Center of World Intelligence Project for Nuclear S \& $\mathrm{T}$ and Human Resource Development by the Ministry of Education, Culture, Sports, Science and Technology of Japan.

\section{References}

[1] Oyama, Y., Zhen, L., Tanabe, T. and Kagaya, M. (2009) Sub-Terahertz Imaging of Defects in Building Blocks. NDT\&E International, 42, 28-33.

https://doi.org/10.1016/j.ndteint.2008.08.002

[2] Takahashi, S., Hamano, T., Nakajima, K., Tanabe, T. and Oyama, Y. (2014) Observation of Damage in Insulated Copper Cables by THz Imaging. NDT\&E International, 61, 75-79. https://doi.org/10.1016/j.ndteint.2013.10.004

[3] Nakamura, Y., Kariya, H., Sato, A., Tanabe, T., Nishihara, K., Taniyama, A., Nakajima, K., Maeda, K. and Oyama, Y. (2014) Nondestructive Corrosion Diagnosis of Painted Hot-Dip Galvanizing Steel Sheets by Using THz Spectral Imaging. Corrosion Engineering, 63, 411-416.

[4] Tanabe, T., Watanabe, K., Oyama, Y. and Seo, K. (2010) Polarization Sensitive THz 
Absorption Spectroscopy for the Evaluation of Uniaxially Deformed Ultra-High Molecular Weight Polyethylene. NDT\&E International, 43, 329-333. https://doi.org/10.1016/j.ndteint.2010.03.001

[5] Zimdars, D., Valdmanis, J.A., White, J.S., Stuk, G., Williamson, S., Winfree, W.P. and Nadaras, E.I. (2005) Technology and Applications of Terahertz Imaging Non-Destructive Examination: Inspection of Space Shuttle Sprayed on Foam Insulation. AIP Conference Proceedings, 760, 570-577.

https://doi.org/10.1063/1.1916726

[6] Niwa, M. and Hiraishi, Y. (2014) Quantitative Analysis of Visible Surface Defect Risk in Tablets during Film Coating Using Terahertz Pulsed Imaging. International Journal of Pharmaceutics, 461, 342-350.

https://doi.org/10.1016/j.ijpharm.2013.11.051

[7] Wahaia, F., Kasalynas, I., Seliutra, D., Molis, G., Urbanowicz, A., Silva, C.D.C., Carneiroe, F., Valusisb, G. and Granja, P.L. (2015) Study of Paraffin-Embedded Colon Cancer Tissue Using Terahertz Spectroscopy. Journal of Molecular Structure, 1079, 448-453. https://doi.org/10.1016/j.molstruc.2014.09.024

[8] Purnell, P., Diamond, G.G., Hutchins, D.A., Gan, T.H. and Leong, K.K. (2005) Capacitive Internal Imaging Technique for Concrete. Abstracts: Cement and Concrete Science, 41-44.

[9] Derobert, X., Iaquinta, J., Klysz, G. and Balayssac, J.-P. (2008) Use of Capacitive and GPR Techniques for the Non-Destructive Evaluation of Cover Concrete. NDT \& E International, 41, 44-52. https://doi.org/10.1016/j.ndteint.2007.06.004

[10] Yin, X., Hutchins, D.A., Diamond, G.G. and Purnell, P. (2010) Non-Destructive Evaluation of Concrete Using a Capacitive Imaging Technique: Preliminary Modelling and Experiments. Cement and Concrete Research, 40, 1734-1743. https://doi.org/10.1016/j.cemconres.2010.08.015

[11] Pankove, J.I. (1971) Optical Processes in Semiconductors. Prentice-Hall, Englewood Cliffs, NJ.

[12] Born, B., Heyden, M., Ebbinghaus, S. and Havenith, M. (2014) Probing Solvation Dynamics by Terahertz Absorption Spectroscopy. In: Son, J.-H., Ed., Terahertz Biomedical Science and Technology, CRC Press/Taylor \& Francis Group, Boca Raton, FL, 135-152.

[13] Penkov, N., Shvirst, N., Yashin, V., Fesenko Jr., E. and Fesenko, E. (2015) Terahertz Spectroscopy Applied for Investigation of Water Structure. Journal of Physical Chemistry B, 119, 12664-12670. https://doi.org/10.1021/acs.jpcb.5b06622 